\title{
Laboreal
}

Volume $8 \mathrm{~N}^{\circ} 2$ | 2012

A antropotecnologia, ferramenta ou engodo?

\section{La antropotecnología : un programa singular en la historia de las ciencias del trabajo}

A antropotecnologia : um programa singular na história das ciências do trabalho L'anthropotechnologie : un programme singulier dans l'histoire des sciences du travail

Anthropotechnology: a specific program in the field of work sciences

\section{Yves Cohen}

Traductor: Carole Baudin

\section{OpenEdition}

Journals

Edición electrónica

URL: http://journals.openedition.org/laboreal/6558

DOI: 10.4000/laboreal.6558

ISSN: 1646-5237

Editor

Universidade do Porto

Referencia electrónica

Yves Cohen, "La antropotecnología : un programa singular en la historia de las ciencias del trabajo », Laboreal [En línea], Volume 8 N² | 2012, Publicado el 01 diciembre 2012, consultado el 11 octubre 2019. URL : http://journals.openedition.org/laboreal/6558; DOI : 10.4000/laboreal.6558

Este documento fue generado automáticamente el 11 octubre 2019

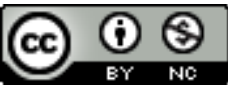

Laboreal está licenciado com uma Licença Creative Commons - Atribuição-NãoComercial 4.0 Internacional. 


\section{La antropotecnología : un programa singular en la historia de las ciencias del trabajo}

A antropotecnologia : um programa singular na história das ciências do trabalho L'anthropotechnologie : un programme singulier dans l'histoire des sciences du travail

Anthropotechnology: a specific program in the field of work sciences

\section{Yves Cohen}

Tradución : Carole Baudin

\section{NOTA DEL EDITOR}

Manuscrito recibido en : Mayo/2012

Aceptado tras peritaje : Agosto/2012

1 La antropotecnología tiene algo singular. Incluso, varios rasgos la hacen singular. Se inscribe en la filiación de la ergonomía. Sin embargo, la ergonomía, siempre me ha sorprendido, reconoce y hasta lleva con orgullo su filiación con Taylor (De Montmollin, 1981). Taylor se presenta como científico, como un análisis científico del trabajo y, al mismo tiempo, una intervención directora sobre el trabajo basada en dicho análisis. Presenta también la ciencia que crea, como el árbitro del conflicto social interno de las empresas. De hecho, en nombre de su cientificidad, los bolcheviques han creído poder tomarlo prestado del capitalismo para aplicarlo al socialismo - no obstante, sin poder nunca lograrlo realmente. Sin embargo, el taylorismo fue constantemente el enemigo de la gente a quien estaba destinado como técnica de control y dirección del trabajo, los obreros y empleados, cualquiera sea su calificación. Fue considerado por categorías enteras del personal de las empresas y administraciones como un arma hostil, patronal, y, más ampliamente, como perteneciendo al poder. La ergonomía, por su lado, se 
considera como una ciencia del trabajo y es en este sentido que también se situó en el camino dejado por el taylorismo. No se trataba de en ningún modo de la táctica un poco grosera de la gente de izquierda truqueando para entrar en las empresas : la ergonomía no quiere tomar partido por una $\mathrm{u}$ otra de las batallas del trabajo.

Desde el periodo de entreguerras, los partidarios de una ciencia del trabajo han cruzado este problema de manera directa. Cerca de los años 1930, tanto en Francia como en Alemania, el campo de lo que se define como psicotécnica, psicofisiología del trabajo y psicología industrial se divide, por un lado, entre los que capacitan profesionales para la industria, $y$, por otro lado, los que creen que una disciplina científica debe estar más atenta a sus implicancias sociales y buscar una legitimidad científica más importante que la psicotécnica en su sólo uso industrial (Rabinbach, 1995 ; Vatin, 1996). Para Otto Lipmann, el principal representante de esta ciencia del trabajo en Alemania, "la persona que trabaja" está siempre en el "centro de atención" (Lipmann in Rabinbach, 1995). Luego, en todos los países donde se desarrolla después de la Segunda Guerra Mundial, la ergonomía se define como la adaptación del trabajo o de la máquina al hombre, rechazando las tendencias industrialistas de ante-guerra, que denuncia, por querer al contrario "adaptar el hombre a su labor[1]" (Wisner, 1996).

3 Como la ergonomía, la antropotecnología lleva en sí una filosofía de la investigación que busca la eficacia de la actividad concebida no solamente para uno de los actores o participantes del juego, sino que para todos, e incluyendo la eficacia económica, cualquiera sean las formas de su cálculo. Al contrario del taylorismo y no más que la ergonomía, la antropotecnología no pretende volverse el árbitro de conflictos políticos o sociales. No quiere ser la "mediadora" entre actores, grupos o colectivos. No arbitra, no actúa como mediadora. Hace pasar, dice. Es una pasadora entre interlocutores y entre grupos, pasadora de saberes, de saber-haceres, de técnicas.

4 Se trata seguramente de un signo de los tiempos que un "campo disciplinario " se desarrolle por un lado, gracias a contratos con organismos variados, públicos, semipúblicos o privados, y, por otro lado, en espacios de debates científicos. Claramente, las actuales condiciones de la investigación en Ciencia Sociales y Humanas en general llevan al desarrollo acelerado de disciplinas de asesoramiento a los estados, a las empresas a las ONG's (Organismos no Gubernamentales). El campo del cual trata este dossier no es aislado. Y, de nuevo como la ergonomía, la práctica de la antropotecnología se sitúa entre una respuesta a un pedido y la participación en la vida científica, en una constante búsqueda de equilibrio. A diferencia de la psicotécnica, de la psicología del trabajo y de la ergonomía que están más bien del lado de las Humanidades, la antropotecnología está del lado de las Ciencias Sociales por el hecho de su segunda filiación en la cual se inscribe : la antropología. No es, sin embargo, una "antropología aplicada" : el carácter de respuesta a un pedido (que es el modo principal pero no exclusivo de lanzamiento de un estudio antropotecnológico) se entrelaza indisolublemente con la dimensión científica de su práctica. El conocimiento es indisociable de la intervención y hasta procede de esta, procede de lo que se transforma, antes de transformarse ella misma. Obviamente, se puede temer el desliz hacia una práctica exclusiva de asesoramiento por una parte importante de las personas capacitadas en la antropotecnología. El desafío es entonces mantener lo más ampliamente posible el enlace intrínseco entre intervención y participación en la vida científica. Este enlace se compone de dos dispositivos. 
5 Primero, como la ergonomía, la antropotecnología se reserva el derecho de "reformular la demanda" en función de sus propias exigencias científicas y éticas. Para este efecto, el estudio etnográfico es un recurso crítico. Sus resultados, cuando han mostrado la divergencia entre las concepciones de quien demanda y las del grupo involucrado (tal como grupo de pescadores o fabricantes de sal), han llevado en varias ocasiones o bien a recomponer significativamente la demanda inicial o bien a romper en el transcurso un contrato ya establecido. La postura que consiste en no jugar para un solo actor llega, en lo concreto de las experiencias, a la confrontación efectiva con los demandantes, los socios del estudio, los intermediarios siempre necesarios, a la confrontación con los más poderosos para resguardar la independencia del punto de vista del estudio y el equilibrio entre sus diversos participantes, cualquiera sea su estatuto. La preservación de esta independencia de juicio es esencial para mantener la articulación entre intervención y abordaje científico.

6 Luego, la antropotecnología tiene la ambición de participar plenamente de la antropología, su segunda fuente con la ergonomía. Sus propuestas tratan sobre la lógica de los objetos y prácticas técnicas, sobre el saber hacer y su identidad (que se fabrica con las circulaciones) y sobre la formalización del saber hacer (que es uno de los ámbitos en el cual la antropotecnología está llevada en intervenir y en pensar). Se manifiestan en particular en la antropología de las técnicas. La orientación más ambiciosa consiste en contar con una multitud de terrenos acumulados a través del mundo e interrogarse sobre lo que es común en ellos en términos de apropiación de las técnicas, de dinámicas de transferencias tecnológicas, de procesos creativos localizados, etc. Se reencuentra aquí un antiguo e insistente proyecto de la antropología interesada en las técnicas : la elaboración de una tecnología en el sentido de ciencia de, o discurso sobre la técnica. Es aquí donde la antropotecnologia puede contar con el apoyo ya recibido de parte de la disciplina antropológica en el sentido amplio, así como con el apoyo de la historia de las técnicas. De hecho, alcanza una ambición del todo comparable a esta última y que comparte con ella: hacerse tecnología. Es el discurso fuertemente asumido por la Historia por Liliane Hilaire-Pérez (2008a, 2008b) cuando sostuvo su trabajo de Tesis Habilitación para Dirigir Investigaciones [2]. La antropotecnología trae en este amplio ámbito de estudio su propia metodología, la que tomó prestada de la ergonomía y que tiene que ver con el análisis del trabajo y de los saber-haceres. Para los historiadores como para los antropotecnólogos que buscan desafiar el reto, siempre relanzado, de formular una tecnología sólida, el reto consiste en captar cada vez singularidades situadas y en pensar estas singularidades en conjunto: para la antropotecnología, la "maleta del pequeño ergonomista" concebida por Alain Wisner entrega medios reproducible para observar las prácticas técnicas e intentar de acercarse a ellas.

7 Desde el punto de vista de una larga historia de las Ciencias del Trabajo (incluyendo la psicología), la antropotecnología presenta otro rasgo singular. Circula. O mejor dicho, los que la llevan, circulan. Hasta ahora, los profesionales de estas ciencias trabajaban exclusivamente en la cercanía : en los países occidentales, los organizadores del trabajo productivo tenían sus oficinas en las puertas de los talleres; y solo se han alejados lentamente de estas, a medida que establecían estándares que ofrecían una generalidad suficiente, y nunca han salido de la empresa en la cual ofician (Chatzis, 1999); la intervención ergonómica de terreno supone, por su lado, la concentración exclusiva sobre localidades muy estrechas para constituir mejor su objeto. 
El antropotecnólogo se desplaza mucho y por varias razones. Puede efectuar distancias continentales o intercontinentales para ir desde un mandante hasta el terreno. En terreno, con la preocupación de identificar, y en caso necesario, de reformular la demanda, llega a visitar no solamente el grupo definido inicialmente sino también cualquier otra entidad a la cual lleva el estudio, a veces cercanos, otras veces, lejanos. Esta preocupación de "extender" las redes para entender mejor las dimensiones pertinentes del estudio puede también llevar en efectuar nuevas distancias continentales. Concebir técnicas de producción de sal solar para las poblaciones del litoral de Guinea y contribuir así a reducir la desforestación de las zonas de manglares ; para acompañar el diseño de tecnologías de producción de oro sin mercurio en África del Oeste y en América Latina ; o, más cercano a nosotros, trabajar en las condiciones de implementación de sistemas de comunicación en una gran empresa, pero también intervenir en los procesos de diseño de equipamientos específicos para expedicionarios polares. La antropotecnología "embarca" en su proyecto a actores captados en lugares lejanos, les hace contactarse, hace "pasar" del uno al otro sus datos, estudios, reflexiones, resultados o los de uno $\mathrm{u}$ otro de los participantes, grupo o individuos. La puesta en circulación -en lo más cercano como en lo más lejanos- y la extensión de las problemáticas, de los métodos, de los elementos de la investigación son entonces constitutivas de la actividad de estos especialistas de la actividad que son los antropotecnólogos. Lo vemos, estos "viajes" no son exactamente del mismo tipo que los de la antropología clásica.

Al igual que la relación entre la intervención y la reflexión científica, es muy notable constatar hasta qué punto la antropotecnología está en su tiempo en este diseño de circulaciones. Dicho de otra forma, está totalmente en fase con las exigencias de una globalización contemporánea que, por otra parte, por la intensificación de la circulación de todas entidades (incluidas infra-nacionales), impone el decentralismo, la multi localización de las investigaciones y su puesta en circulación así como la de los investigadores y de los que colaboran con las investigaciones, cualquiera sea su título.

10 Para evocar la antropotecnología, Philippe Geslin no emplea el término de disciplina. Humildad o estrategia, prefiere la expresión de campo disciplinario. No importa, estamos en presencia de una práctica científica y al mismo tiempo una práctica de intervención que tiene ya una historia. Con la persona de Alain Wisner, quien formuló el primer programa de esta disciplina, la antropotecnología se inscribe en la línea de las disciplinas del trabajo, ya que este médico, también egresado de la escuela de la psicofisiología del trabajo francesa ha introducido, con algunos otros, la ergonomía en Francia (Clot, 1996). En la medida que Philippe Geslin, quien ha hecho de la propuesta de Wisner una práctica efectiva, tiene una formación y una práctica constante de antropólogo, tanto en su investigación como en su enseñanza, el "campo" viene también de la línea antropológica. La antropotecnología tal como se está desarrollando actualmente tiene un doble carácter que funciona en cruce : es una antropología con una metodología de estudio del trabajo viniendo de la ergonomía y una ergonomía nutrida por el estudio etnográfico y la elaboración etnológica.

11 De la antropología rechaza la herramienta analítica de las prácticas técnicas, que se ha vuelto el estándar clásico : la "cadena operatoria". Insuficiente, ésta, así como, por otra parte, la "observación participante" de los sociólogos, no permite para Geslin alcanzar la lógica de los gestos. Se necesita la "maleta del pequeño ergonomista" y sus herramientas de análisis, cronómetros, hojas de rutas, recolección analítica de los 
movimientos, de las relaciones entre los diversos participantes de la actividad, gráficos de la actividad, etc., sin hablar de la práctica de auto-confrontación tomada de Jacques Thereau (2006) que consiste en grabar la actividad, proyectarla a las personas a las cuales se les pide explicitar - sin salir de la lógica del curso de acción - tales gestos o movimientos efectuados o tales palabras expresas. La lógica del curso de acción es considerada en la dinámica misma de los actores y en el sentido que ellos dan a sus actos y a las relaciones que estos actos suponen con las personas así como con los objetos. Antropología entonces, con herramientas de análisis de la ergonomía.

En el otro sentido, la antropotecnología es un tipo de ergonomía pero con la exigencia de captar la actividad solo después de haber realizado un estudio etnográfico antes. Se encuentran obviamente ergónomos que recurren también a la etnografía de su terreno articulándola con el análisis de la actividad. La antropotecnologia, sin embargo, utiliza todo el repertorio antropológico. Una noción fundamental desarrollada por Philippe Geslin es la de "memoria local de desarrollo". Esta noción contribuye a singularizar el lugar de la intervención (un pueblo, un terroir, un distrito, una ciudad, etc.) tomando solo características antropológicas generalizantes construidas para entender todo un grupo o una población. ¿Cuál es la historia local delimitada de las prácticas formadas por la confrontación con intervenciones externas? ¿Cuáles son los rasgos de esta confrontación?

Esta elaboración de la " memoria local de desarrollo » participa a la singularización de una actividad situada como el análisis ergonómico del trabajo lo hace por lo que aporta de su lado.

Disciplina singular por varias razones, la antropotecnología se centra en captar singularidades bajo varios ángulos (análisis, etnografía, extensión circulatoria del estudio, historia), singularidades que su carácter científico, mantenido a toda fuerza, trata de pensar en conjunto.

\section{BIBLIOGRAFÍA}

Bonnardel, R. (1943). L'adaptation de l'homme a son métier. Paris: PUF.

Chatzis, K. (1999). Searching for Standards: French Engineers and Time and Motion Studies of Industrial Operations in the 1950s. History and Technology, 15(3), 233-261.

Clot, Y. (1996). Les histoires de la psychologie du travail. Toulouse : Octarès.

De Montmollin, M. (1981). Le taylorisme à visage humain. Paris : PUF.

Hilaire-Perez, L. (2008a). Inventer une recherche en histoire des techniques, mémoire de synthèse, dossier pour l'Habilitation à Diriger des Recherches (HDR), Université Paris 1, 157 pp.

Hilaire-Perez, L. (2008b). La pièce et le geste. Entreprise, cultures opératoires et marchés à Londres au XVIIIe siècle. Document inédit pour l'HDR, université Paris 1, 3 vol.

Rabinbach, A. (1995). La psychologie industrielle dans l'Allemagne de Weimar, entre psychotechnique et politique : le cas d'Otto Lipmann. In Yves Cohen et Rémi Baudouï (Dirs.), Les 
Chantiers de la paix sociale. 1900-1940 (pp. 127-156). Fontenay-aux-Roses, ENS-Éditions Fontenay Saint-Cloud.

Theureau, J. (2006). Le cours d'action. Méthode développée. Toulouse, Octarès.

Vatin, F. (1996). De la naissance de la psychologie appliquée au débat sur le taylorisme. Autopsie d'un échec : le cas français (1890-1920). In Y. Clot (Dir.), Les histoires de la psychologie du travail (pp. 47-68). Toulouse : Octarès.

Wisner, A. (1996). Itinéraire d'un ergonomiste dans l'histoire de la psychologie contemporaine. In Y. Clot (Dir.), Les histoires de la psychologie du travail (pp. 99-111). Toulouse : Octarès.

\section{NOTAS}

1. El sucesor de J.M. Lahy en la Cátedra de Psicología del trabajo a la Ecole Pratique des Hautes Etudes (Escuela Practica de Altos Estudios), Raymond Bonnardel, escribió en 1943 una obra intitulada "La adaptación del hombre a su labor".

2. Nota del traductor: en Francia, después del doctorado, los investigadores presentan una "habilitación para dirigir investigaciones" en la cual se debe realizar una tesis para poder guiar luego otros trabajos doctorales.

\section{RESÚMENES}

Al mismo tiempo que reposiciona la antropotecnología en la historia de las Ciencias del Trabajo, este texto busca definir este campo disciplinario, a través de las singularidades de su postura teórica y práctica. Entre antropología y ergonomía, la antropotecnología se construyó, a lo largo de sus experiencias de campo, un espacio particular en el horizonte científico y pragmático.

Ao mesmo tempo que reposiciona a antropotecnologia na história das Ciências do Trabalho, este texto procura definir este campo disciplinar através das singularidades da sua postura teórica e prática. Entre antropologia e ergonomia, a antropotecnologia construi, ao longo das suas experiências no terreno, um espaço particular no horizonte científico e pragmático.

En repositionnant l'anthropotechnologie dans l'histoire des Sciences du travail, ce texte cherche à définir ce champ disciplinaire, à travers les singularités de sa posture théorique et pratique. Entre anthropologie et ergonomie, l'anthropotechnologie s'est sculptée au fil de ses différentes expériences de terrains, un espace particulier dans l'horizon scientifique et pragmatique.

This paper is repositioning anthropotechnology in the history of work sciences. It defines this disciplinary field, through the singularities of its theoretical and practical postures. Between anthropology and ergonomics, anthropotechnology was carved over its various field work experiences, a particular space in the scientific and pragmatic horizon. 
ÍNDICE

Palabras claves: intervención y postura antropotecnológica, ergonomía, antropología, historia Keywords: applied anthropology, anthropotechnology, ergonomics, anthropology, history Palavras-chave: intervenção e postura antropotecnológica, ergonomia, antropologia, história Mots-clés: intervention et posture anthropotechnologique, ergonomie, anthropologie, histoire

\section{AUTORES}

\section{YVES COHEN}

EHESS - CRH (École des Hautes Études en Sciences Sociales - Centre de Recherches Historiques), 190-198, avenue de France - 75244 Paris cedex 13

yvecohen@free.fr 